American Journal of Infectious Diseases 4 (1): 50-59, 2008

ISSN 1553-6203

(C) 2008 Science Publications

\title{
Generation of Anti-platelet Autoantibody During Dengue Virus Infection
}

\author{
${ }^{1}$ Kao-Jean Huang, ${ }^{1}$ Yee-Shin Lin, ${ }^{1}$ Hsiao-Sheng Liu, \\ ${ }^{2}$ Trai-Ming Yeh, ${ }^{3}$ Ching-Chuan Liu and ${ }^{1}$ Huan-Yao Lei \\ ${ }^{1}$ Department of Microbiology and Immunology, College of Medicine, \\ National Cheng Kung University, Tainan, Taiwan, Republic of China \\ ${ }^{2}$ Department of Medical Technology, College of Medicine, \\ National Cheng Kung University, Tainan, Taiwan, Republic of China \\ ${ }^{3}$ Department of Pediatrics, College of Medicine, National Cheng Kung University, \\ Tainan, Taiwan, Republic of China
}

\begin{abstract}
Dengue virus infection causes dengue fever, Dengue Hemorrhagic Fever (DHF) and Dengue Shock Syndrome (DSS). Thrombocytopenia is common in dengue fever and is always found in DHF/DSS. The pathogenesis of thrombocytopenia is poorly understood. To further understand the relationship between anti-dengue virus antibody and anti-platelet antibody, we generated monoclonal anti-dengue virus antibodies from the dengue virus infected mice that developed transient thrombocytopenia post dengue infection. The analysis of a panel of monoclonal anti-NS-1 antibodies reveals three different patterns of platelet binding: strong, intermediate, or dull. Their isotypes are different, some are IgM while others are $\mathrm{IgG}_{1}$. Most of anti-platelet antibodies are cross-reactive with NS-1 of dengue virus and can be competitively inhibited by recombinant NS-1 protein, suggesting a molecular mimicry between dengue virus NS-1 protein and platelet. A clone, 13-F4-G5, preferentially bound activated platelets, can recognize two or three proteins around $150 \mathrm{kD}$ on platelets. The binding to platelet would lyse the platelet in the presence of complement or enhance the ADP-induced platelet aggregation. Furthermore, some of these monoclonal antibodies would also react with the cellular antigens of BHK. Based on the data, we conclude that dengue virus infection induces auto anti-platelet antibodies which thereafter may involve in the manifestation of thrombocytopenia. A molecular mimicry between NS-1 and platelet is demonstrated.
\end{abstract}

\section{Key words:}

\section{INTRODUCTION}

Dengue Fever (DF) is an acute infectious disease caused by dengue virus which has four serotypes. It is characterized by biphasic fever, headache, pain in various parts of the body, rash, lymphadenopathy and leukopenia. In most cases, the disease of dengue fever is self-limited. However, there is risk to progress into Dengue Hemorrhagic Fever (DHF) or Dengue Shock Syndrome (DSS) especially when cross infection of different serotypes occurs.

DHF is a severe febrile disease characterized by abnormalities of hemostasis and increased vascular permeability, which in some instances results in DSS. DSS is a form of hypovolemic shock that is associated clinically with hemoconcentration and frequently leads to death if appropriate care is not given ${ }^{[1-3]}$. Thrombocytopenia is common in dengue fever and is always found in DHF/DSS. Its pathogenesis is poorly understood. La Russa and Innis reported dengue-virusinduced bone marrow suppression that depressed platelet synthesis ${ }^{[4]}$. Wang et al., found that dengue-2 virus can bind to human platelets in the presence of virus-specific antibody ${ }^{[5]}$.

We also reported the presence of IgM anti-platelet auto-antibody in the sera of dengue patients and its titer is higher in DHF/DSS patients than in DF patients ${ }^{[6]}$. To further understand the relationship between anti-dengue virus antibody and anti-platelet antibody, a murine model of dengue virus infection was setup. Transient thrombocytopenia developed at 10-13 days after primary or secondary infection and was associated with the generation of anti-platelet antibody ${ }^{[7]}$. A panel of monoclonal antibodies was generated from these dengue virus-infected mice. In this study, it was reported that anti-dengue virus antibodies, especially

Corresponding Author: Huan-Yao Lei, Department of Microbiology and Immunology, College of Medicine, National Cheng Kung University, Tainan, Taiwan, Republic of China, Tel: 886-6-2353535 
anti-NS-1 ones, could cross-react with platelet. The molecular mimicry between dengue virus and self-antigens was discussed.

\section{MATERIALS AND METHODS}

Mice and cell culture: Breeder mice of BALB/c strain were purchased from The Jackson Laboratory, Bar Harbor, ME or Charles River Japan, Inc. (Atsugi, Japan). They were maintained on standard laboratory chow and water ad libitum in the animal facility of the Medical College, National Cheng Kung University, Tainan, Taiwan. The animals were raised and cared for following the guidelines set up by the National Science Council of the Republic of China. Six to twelve-weekold mice were used in all experiments. BHK and K562 cells were grown in DME medium containing $10 \%$ FBS.

Dengue virus preparation: A local isolate of dengue virus type 2 (PL046) was supplied by the Institute of Preventive Medicine, Nan Kung, Taipei, Taiwan. Viruses were propagated in mosquito C6/36 cell line which were incubated in Eagle's minimal essential medium containing $2 \%$ heat-inactivated FBS at $28^{\circ} \mathrm{C}$ for 5 days $^{[8]}$. Each virus pool can obtain a titer of $1 \times 10^{8}$ PFU $\mathrm{mL}^{-1}$ by standard methods on BHK cells ${ }^{[9]}$. To purify the dengue virus antigen, the pooled virus stocks were first concentrated by ultra-filtration of $10 \mathrm{kDa}$ cutoff membrane, then centrifuged at $10,000 \times \mathrm{g}$ for $10 \mathrm{~min}$. The supernatant was further centrifuged at $100,000 \times \mathrm{g}$ for $3 \mathrm{~h}$ to pellet the dengue virus particle. This procedure can enrich virus stock to $1 \times 10^{11} \mathrm{PFU} \mathrm{mL}^{-1}$. The semi-purified dengue virus was used in the ELISA to screen the anti-dengue antibody.

Virus infected cells: BHK or K562 cells were maintained in Dulbecco's modified eagle medium containing $2 \%$ heat-inactivated FBS at $37^{\circ} \mathrm{C}$ and infected by either Japanese encephalitis virus (JEV) or dengue virus at the m.o.i. $=5$. Cells were harvested at $48 \mathrm{~h}$ post infection and subjected to flow cytometric analysis. In some studies, BHK cells were grown in the Lab-Tek chamber slide system (Nalge Nunc International, Naperville, IL). They were infected at m.o.i. $=1$ for $48 \mathrm{~h}$. The dengue antigen was detected with 13-F4-G5 $\mathrm{mAb}$ and second goat anti-mIgG peroxidase conjugate. A peroxidase stain with a reddish brown color was developed with an aminoethyl carbazole substrate kit (ZYMED Laboratories, San Francisco, CA) and counterstained with 1\% Evans blue.
In the preparation of dengue virus infected cell lysates, C6/36 cell was maintained in Eagle's minimal essential medium containing $2 \%$ heat-inactivated FBS at $28^{\circ} \mathrm{C}$ and was infected by dengue virus at m.o.i. $=1$. After 5 days of incubation, cells were harvested and then lysed in RIPA buffer and used as the dengue virus antigen source.

Generation of monoclonal antibody from dengue-2virus-infected mice: Groups of $\mathrm{BALB} / \mathrm{c}$ mice were inoculated intravenously with dengue virus $\left(1 \times 10^{8}\right.$ PFU). The mice were sensitized for 3 or 4 times at onemonth interval with $1 \times 10^{7}$ PFU. Before the fusion, the mice were boosted with $1 \times 10^{6}$ PFU for three days. The splenocytes were fused with FO myeloma using $1 \%$ PEG as described previously ${ }^{[10]}$. Several methods including ELISA on dengue virus or dengue virus infected cells, or anti-platelet binding by flow cytometry were used to screen the antibodies.

Detection of anti-platelet or anti-dengue antibody by FACScan: Human peripheral blood collected in sodium EDTA was centrifuged at $100 \times \mathrm{g}$ for $10 \mathrm{~min}$ at room temperature. The upper layer as platelet-rich plasma was removed to a 15-ml tube, mixed with $0.34 \%$ EDTA in phosphate-buffered saline (PBS) and centrifuged at $1000 \times \mathrm{g}$ for $15 \mathrm{~min}$. The pellets were washed 3 times with $0.34 \%$ EDTA-PBS and fixed in 10 $\mathrm{ml}$ of $1 \%$ formaldehyde in PBS at room temperature for $10 \mathrm{~min}$. The fixed platelet suspension was centrifuged at $1000 \times \mathrm{g}$ for $15 \mathrm{~min}$. The pellets were washed in PBS twice and resuspended in $2 \mathrm{ml}$ of PBS.

The platelet count was determined using a hemacytometer. The anti-platelet antibody binding was determined with flow cytometric analysis as described previously $^{[11]}$. Platelets $\left(2.5 \times 10^{6} \quad 0.1 \quad \mathrm{~mL}^{-1}\right)$ were incubated with monoclonal antibody for $60 \mathrm{~min}$ on ice, then washed twice with PBS. The second goat antimouse IgG FITC-conjugated antibody (Cappel, Organon Teknika, N.V. Belgium) was added and the mixture was incubated for $40 \mathrm{~min}$ on ice. After washing twice with PBS, the platelets were suspended in PBS and analyzed by FACScan (Becton-Dickinson, Mountain View,CA) with excitation set at $488 \mathrm{~nm}$. In some experiments, BHK or K562 cells infected with dengue virus at m.o.i. $=5$ for $48 \mathrm{~h}$ were used. For intracellular staining, cells were treated with fixation buffer containing 4\% paraformaldehyde followed by permeabilization buffer containing $0.1 \%$ saponin. 
Platelet lysates: Normal human blood was collected in a tube containing $0.33 \%$ sodium citrate at 9:1 ratio, then was centrifuged at $200 \times \mathrm{g}$ for $20 \mathrm{~min}$ under room temperature. The platelet-rich plasma (PRP) was collected and further centrifuged at $1000 \times \mathrm{g}$ for $10 \mathrm{~min}$. The platelet pellet was gently resuspended in HEPES buffer (134 mM NaCl, $12 \mathrm{mM} \mathrm{NaHCO}$, $2.9 \mathrm{mM} \mathrm{KCl}$, $0.34 \mathrm{mM} \mathrm{Na} \mathrm{HPO}_{4}, 1 \mathrm{mM} \mathrm{MgCl} 2,10 \mathrm{mM}$ hepes, $5 \mathrm{mM}$ glucose, $0.3 \%$ BSA, $\mathrm{pH} 7.4$ ) and platelet number was counted with a hemacytometer. Platelets were activated by thrombin at concentration of $1 \mathrm{U} \mathrm{mL}^{-1}$. After $5 \mathrm{~min}$ of incubation, the platelets were washed twice with HEPES buffer at $1000 \times \mathrm{g}$ for $10 \mathrm{~min}$ and lysed in RIPA buffer (1\% Triton X-100, 0.5\% sodium deoxycholate, $0.1 \%$ SDS, $150 \mathrm{mM} \mathrm{NaCl}, 1 \mathrm{mM}$ EGTA, $50 \mathrm{mM}$ Tris $\mathrm{pH}$ 7.6).

Platelet aggregation test: The platelet-rich plasma was collected as previously described. The remaining portion was further centrifuged at $1200 \times \mathrm{g}$ for $10 \mathrm{~min}$ at room temperature to collect the platelet-poor plasma (PPP). Aggregation test was done with the instruction of the aggregometer (Hema Tracer 2, Niko Bioscience). Different concentrations of monoclonal antibody were incubated with PPP for $10 \mathrm{~min}$ before adding platelet agonist, ADP. Platelet aggregation was recorded for $10 \mathrm{~min}$.

Western blot: Samples for electrophoretic analysis were disrupted for $5 \mathrm{~min}$ at $100^{\circ} \mathrm{C}$ in $0.125 \mathrm{M}$ Tris- $\mathrm{HCl}$ ( $\mathrm{pH}$ 6.8) containing 2.5 SDS, 5 2-ME and $10 \%$ glycerol. Bromophenol blue was added as a tracking dye. Separation gel with 12 acrylamide, 0.1 SDS and $0.375 \%$ Tris- $\mathrm{HCl}$ ( $\mathrm{pH}$ 8.8) and stacking gel of 4 acrylamide, 0.1 SDS and $0.125 \%$ Tris- $\mathrm{HCl}(\mathrm{pH} 6.8)$ were prepared. An equivalent amount of protein prepared from platelets was loaded into the gel. Electrophoresis was performed at $20 \mathrm{~mA} / \mathrm{gel}$ until the bromophenol blue line reached the bottom of the gel. After electrophoresis, gels were transblotted to nitrocellulose paper with $25 \mathrm{mM}$ Tris, $192 \mathrm{mM}$ glycine in a transblot apparatus at $70 \mathrm{~V}$ for $3 \mathrm{~h}$. After transfer, a small strip was cut and stained with amido black to check the transfer of the protein. The nitrocellulose paper was then blocked with $1 \%$ BSA. The platelet proteins recognized by anti-platelet antibody were determined. The goat anti-mouse IgG peroxidase conjugate (Cappel, Organon Teknika, N.V. Belgium) was used as secondary antibodies. The color was developed with PBS containing $0.05 \%$ 4-chlor-1naphthol and $0.01 \% \mathrm{H}_{2} \mathrm{O}_{2}{ }^{[12]}$.
Preparation of recombinant NS-1: The full length dengue-2 virus NS1 cDNA was cloned to pRSET B expression vector (Invitrogen) to establish a pRSETDVNS1 plasmid. After the sequences at 5' and 3' junctions were confirmed, this plasmid was then introduced into $E$. coli BL21 (DE3) pLysS strain (Invitrogen). The recombinant NS1 (rNS1) proteins were induced by IPTG and purified with TALON metal affinity resin (Clontech). A single band was observed by SDS-PAGE analysis and the protein sequence was confirmed by an Applied Biosystems 477A autosequencer.

Antibody - mediated complement - dependent cytotoxicity of platelets: The platelet-rich plasma was centrifuged on the BSA step-gradient (consisting of 50, $25,17,12$ and $10 \% \mathrm{BSA}$ ) at $1500 \times \mathrm{g}$ for $15 \mathrm{~min}$ at room temperature. The platelet fraction was collected and gel-filtrated with a Sepharose 2B (Sigma) column that was pre-equilibrated with HEPES buffer. Platelets $\left(1 \times 10^{8}\right.$ platelets) in 96-well plate were incubated with protein-G purified monoclonal antibodies in the presence of rabbit complement (1:25 dilution) for $4 \mathrm{~h}$. The plate was then centrifuged at $1500 \times \mathrm{g}$ for $15 \mathrm{~min}$ to collect the supernatant. The supernatant $(100 \mu \mathrm{L})$ was transferred into 96-well ELISA plate and mixed with $100 \mu \mathrm{L}$ of the lactase dehydrogenase substrate (Boehringer Mannheim, Mannheim, Germany). The OD was read at $450 \mathrm{~nm}$ after $30 \mathrm{~min}$ with ELISA reader. Cytotoxicity was calculated following the instruction of LDH cytotoxicity assay.

\section{RESULTS AND DISCUSSION}

Different patterns of platelet binding by monoclonal antibodies derived from dengue - $\mathbf{2}$ - virus - infected mice: Dengue virus infection can induce anti-platelet antibodies in human or mice ${ }^{[6,7]}$. The relationship between anti-dengue virus antibody and autoantibody was elucidated with monoclonal antibodies generated from dengue virus-infected mice. ELISA binding on either dengue antigen or dengue virus infected cell was used to screen the anti-dengue virus antibodies. We are particularly interested in the cross-reactive autoantibodies, therefore, the anti-platelet binding by FACScan analysis was also used to screen the monoclonal antibodies. More than 20 different clones were generated from several fusions. 
Among the anti-platelet antibodies, Fig. 1 showed several monoclonal antibodies that react with human platelet. Three patterns of platelet binding were observed based on the degree of fluorescent intensity. Each category of platelet binding had several clones, only representative ones were shown. The strong binding clones are 11-F6-C3, 3-D7-D3, 13-F4-G5, 15-B11-D10 and 16-G3-C3; the intermediate binding, 15-G10-B9; the dull binding, 8-F1-B6.

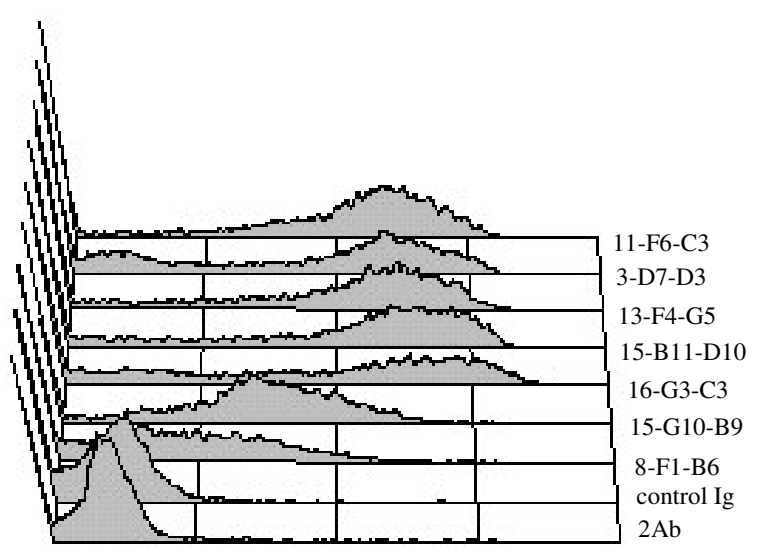

Fig. 1: Platelet-binding profiles of anti-dengue monoclonal antibodies. Fixed platelets $\left(3 \times 10^{6}\right)$ were incubated with culture supernatant from different hybridoma clones at room temperature for $30 \mathrm{~min}$ and then washed twice before staining with fluorescence-conjugated secondary antibody. Binding intensity was analyzed by Flow cytometry

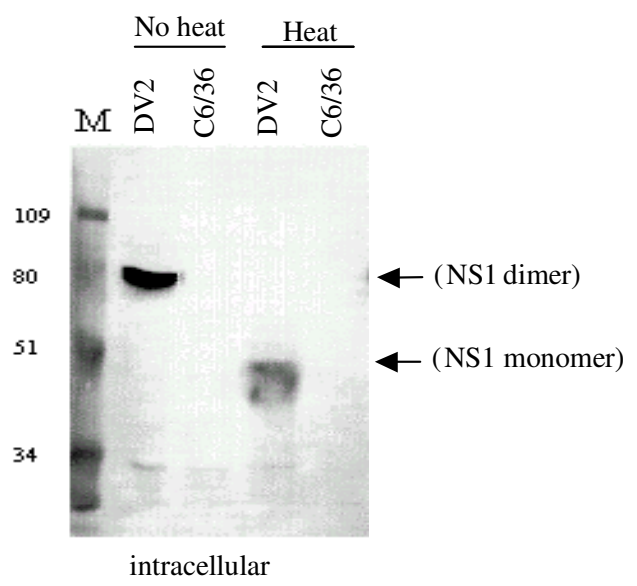

(a)

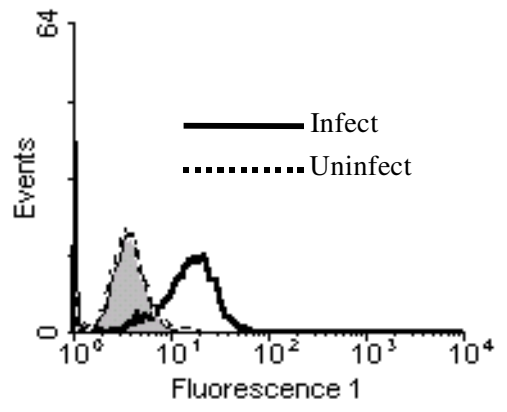

(b)

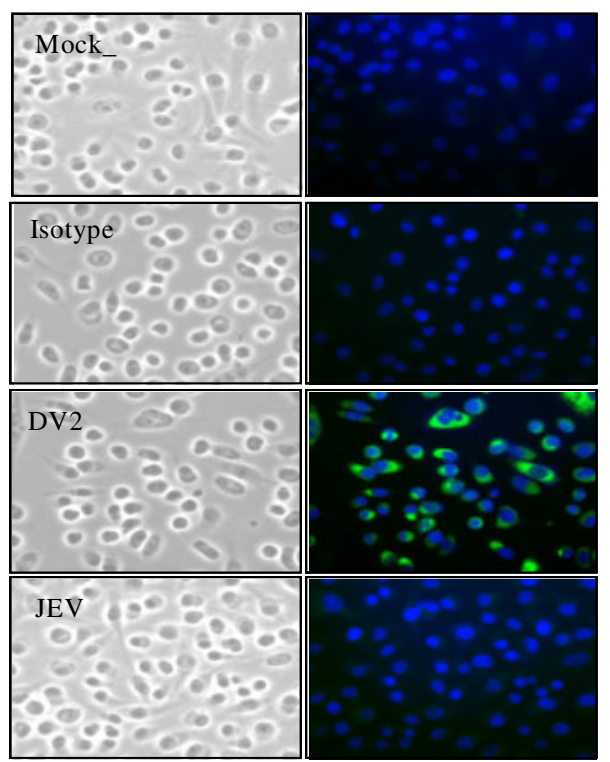

(c)

Fig. 2: Characterization of 13-F4-G5 monoclonal antibody.(a) Western blot assay of 13-F4-G5 with DV2-infected C6/36 lysate. Dengue virusinfected $\mathrm{C} 6 / 36$ cell lysate was prepared and denatured (with 2-ME at $95^{\circ} \mathrm{C}$ for $5 \mathrm{~min}$ ) or not as the viral antigen source for western blot. Mock-infected cell lysate was used as control. (b) Flow cytometric detection of binding of 13F4-G5 to DV2-infected BHK cells. BHK cells were infected with DV2 at the m.o.i. of 5 for 24 $\mathrm{h}$ and assayed by flow cytometry. Mockinfected cells were used as control. (c) Immunofluorescence study of binding of 13-F4G5 to DV2- or JEV- infected BHK cells. BHK cells were mock infected or infected with JEV or DV2 at the m.o.i. of 1 for $24 \mathrm{~h}$ and stained with 13-F4-G5 followed by staining with FITClabeled goat anti-mouse $\operatorname{IgG}$ secondary antibody. Isotype-matched immunoglobulin was used as control 
Am. J. Infect. Dis., 4 (1): 50-59, 2008

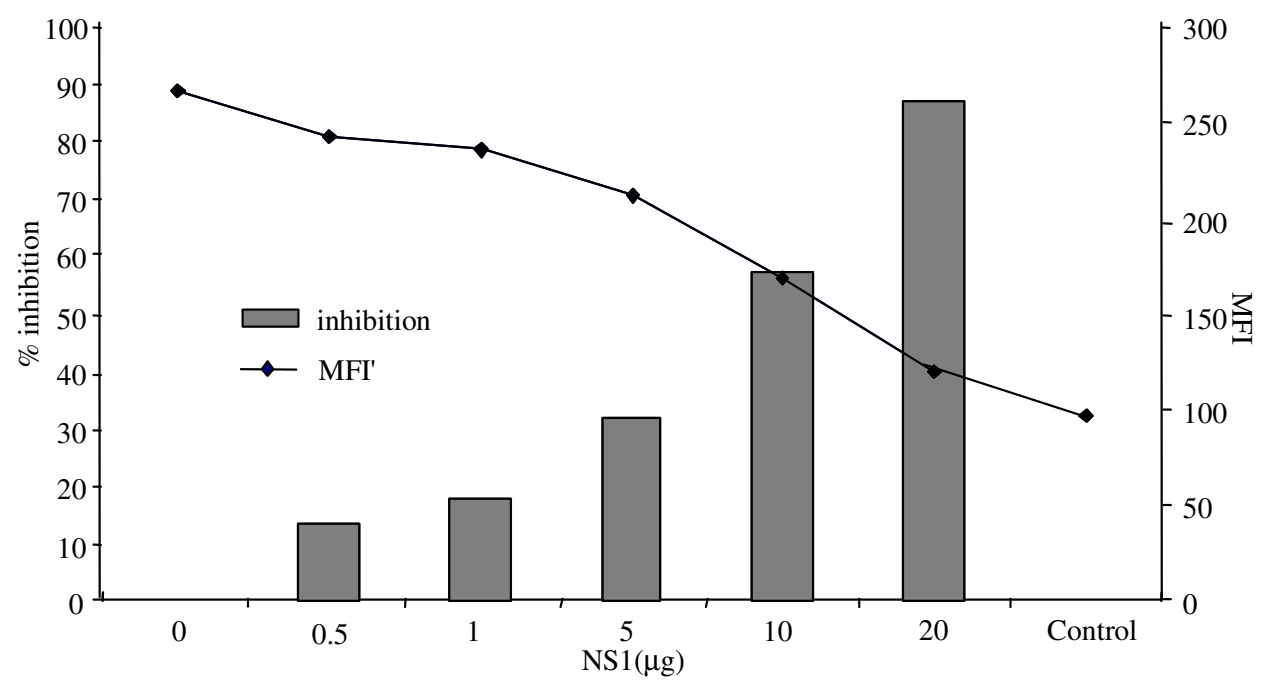

Fig. 3: Dose-dependent inhibition of 13-F4-G5 binding to platelets by recombinant NS-1 antigens. 13-F4-G5 mAbs $(10 \mu \mathrm{g})$ was pre-incubated with various amounts of recombinant NS1 proteins before incubating with $\sim 1 \times 10^{7}$ platelets. Binding was determined by flow cytometry. The percentage of inhibition was calculated as (the MFI of control group-the MFI of experiment group)/the MFI of control group* $100 \%$

Their immunoglobulin classes are different; 3-D7D3 and 8-F1-B6 are $\operatorname{IgM}$ while the rest are $\mathrm{IgG}_{1}$.

Cross-reactivity between dengue virus NS-1 protein and platelet or other self-antigens: Among the antiplatelet antibodies, the dengue antigen specificity was determined. It was found that 13-F4-G5 can specifically recognize the dengue virus, but not Japanese encephalitis virus antigen as shown by immunohistochemical staining and FACScan analysis on dengue virus infected BHK cells (Fig. $2 b$ and c). To determine which protein is recognized, dengue 2 virusinfected C6/36 cell lysate was run on PVP membrane and stained with 13-F4-G5 antibody. As shown in Fig. $2 \mathrm{a}$, it is the NS-1 from dengue virus infected $\mathrm{C} 6 / 36$ cell lysate that was bound by 13-F4-G5 on Western blot. Clones such as 8-F1-B6, 15-G10-B9, 11-F6-C3, 3-D7D3 and 13-F4-G5 can bind recombinant NS-1 protein by ELISA, but 15-B11-D10 and 16-G3-C3 are not NS1-reactive (data not shown). Using NS-1 to competitively block the binding, the platelet binding of 13-F4-G5 could be dose-dependently inhibited (Fig. 3).

This suggests that a cross-reactive epitope between NS-1 and platelet antigen was recognized by 13-F4-G5 monoclonal antibody. The platelet antigens recognized by 13-F4-G5 were then further determined by Western blot analysis on platelet lysate. Several bands with high molecular weight around $150 \mathrm{kDa}$ were recognized by 13-F4-G5 (Fig. 4a), the binding were more intensive on thrombin $\left(1 \mathrm{U} \mathrm{mL} \mathrm{mL}^{-1}\right)$-treated platelet than untreated platelet. This indicates that 13-F4-G5 preferentially recognize activated platelets. This preferential binding by 13-F4-G5 on thrombin-activated platelet was also demonstrated with FACScan analysis (Fig. 4b). The fluorescent intensity of 13-F4-G5 binding was higher in thrombin-treated platelet than non-treated platelet. Furthermore, P1 (amino acids 1-15) is the immunodominant linear epitope of NS-1 recognized by dengue patient sera ${ }^{[13]}$. We tested whether P1 is also dominant in these anti-NS-1 antibodies. Only 8-F1-B6 recognized the P1-peptide, the rest of anti-NS-1 antibodies are P1-peptide binding negative (data not shown).

The cross-reactivity with other cellular antigens was further demonstrated by FACScan analysis on dengue virus infected cells. Surface or intracellular staining was used to localize the antigen on membrane or in cytoplasm, respectively. Both 13-F4-G5 and 15B11-D10 recognized dengue virus infection-induced antigen in cytoplasm (Fig. 5). But 3-D7-D3 would stain BHK intracellularly irrespective of the dengue virus infection, which suggests that 3-D7-D3 recognized cellular antigen of BHK. Similarly, 11-F6-C3, 16-G3C3 and 15-G10-B9 could stain the BHK cells on the surface and intracellularly, which indicats that the cellular antigen of BHK recognized by these mAbs is expressed on the cell surface. The 15-G10-B9 recognized the surface antigen of BHK cells. 
Am. J. Infect. Dis., 4 (1): 50-59, 2008

Table 1: Summary of anti-platelet mAb derived from dengue virus infected mice

\begin{tabular}{|c|c|c|c|c|c|c|}
\hline $\mathrm{mAb}$ & Isotype & NS-1 & P1 & Anti-platelet & Dengue-specific & BHK cell \\
\hline & & binding & Epitope & binding (MFI) & binding & binding \\
\hline 8-F1-B6 & IgM & + & + & $10-30$ & - & Cytoplasm \\
\hline 15-G10-B9 & $\operatorname{IgG}_{1}$ & + & - & $10-100$ & - & Surface \\
\hline 11-F6-C3 & $\operatorname{IgG}_{1}$ & + & - & $100-1000$ & - & Surface \\
\hline 3-D7-D3 & IgM & + & - & $100-1000$ & - & Cytoplasm \\
\hline 13-F4-G5 & $\operatorname{IgG}_{1}$ & + & - & $100-1000$ & + , in cytoplasm & - \\
\hline 15-B11-D10 & $\mathrm{IgG}_{1}$ & - & $\mathrm{NT}^{*}$ & $100-1000$ & + , in cytoplasm & - \\
\hline 16-G3-C3 & $\mathrm{IgG}_{1}$ & - & NT & $100-1000$ & - & Surface \\
\hline
\end{tabular}

*NT, not test

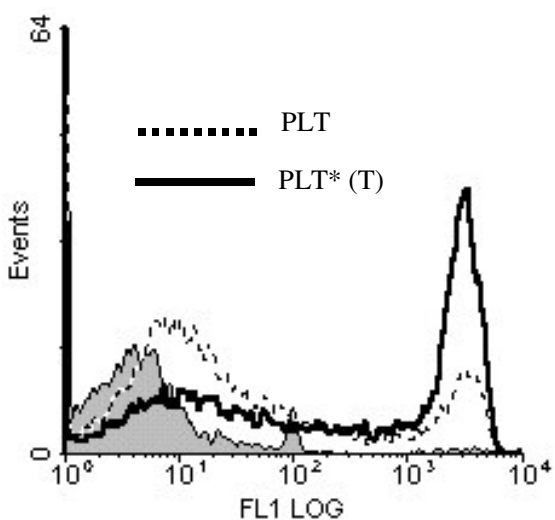

(a)

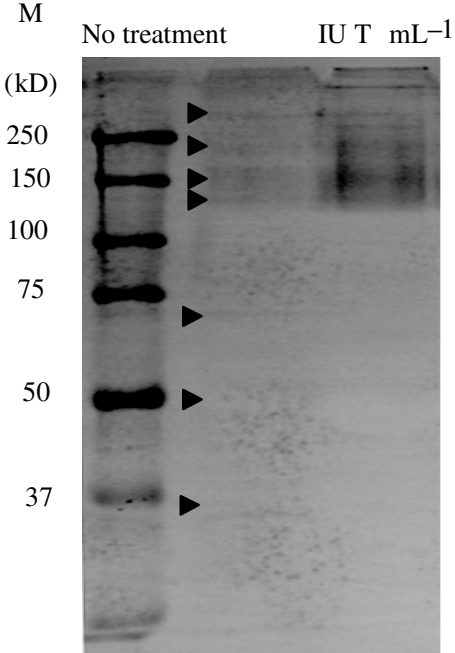

(b)

Fig. 4: Preferential binding of 13-F4-G5 to thrombin-activated platelets. (a) Flow cytometric analysis of binding of 13-F4-G5 to activated platelets. Platelets were activated or not by thrombin at concentration of $1 \mathrm{U} \mathrm{mL}^{-1}$ for $10 \mathrm{~min}$. After fixation with $1 \%$ formaldehyde/PBS for $10 \mathrm{~min}$, platelets were then stained with 13-F4-G5 followed by incubation of FITC-conjugated secondary antibody. Binding was analyzed by flow cytometry. (b) Western blot assay for the molecules recognized by 13-F4-G5. Total proteins from thrombin-activated platelets were subjected to $12.5 \%$ SDS-PAGE eletropheresis and western-blotted with 13-F4-G5

We have repeated the binding assay using K562 cell and obtained the same pattern of binding with these mAbs (data not shown). Individual clone has its own characteristic features with regard to the binding of $\mathrm{P} 1$, NS-1, platelet, or BHK cells, as summarized in Table 1. This suggests that cross-reactivity between dengue virus NS-1 protein and self-antigens does exist.

The effect of anti-platelet antibody on platelet function: When the platelet was incubated with monoclonal antibody, we did not observe the platelet degranulation by ${ }^{3} \mathrm{H}$-serotonin release assay (data not shown). However, in the presence of complement, 13F4-G5, 11-F6-C3 and 15-B11-D10-binding platelets would be lysed (Fig. 6). Moreover, anti-platelet $\mathrm{mAb}$ would enhance the ADP-induced platelet aggregation.
At suboptimal amount of ADP $(5 \mu \mathrm{M})$, the platelet aggregation was enhanced by 13-F4-G5 in a dosedependent manner (Fig. 7). 13-F4-G5 alone or together with goat anti-mIgG antibodies did not cause the platelet aggregation spontaneously.

Based on the data above, we conclude that antidengue virus, especially anti-NS1, antibodies would cross-react with platelet as well as cellular self-antigen and cause their dysfunction. Thrombocytopenia is characteristic of dengue virus infection. Anti-platelet IgM autoantibodies whose titers are higher in DHF/DSS patients than in DF patients ${ }^{[6]}$ may involve in its pathogenesis. We used the dengue virus infected mice that developed transient thrombocytopenia post infection to generate various monoclonal anti-dengue virus antibodies. 

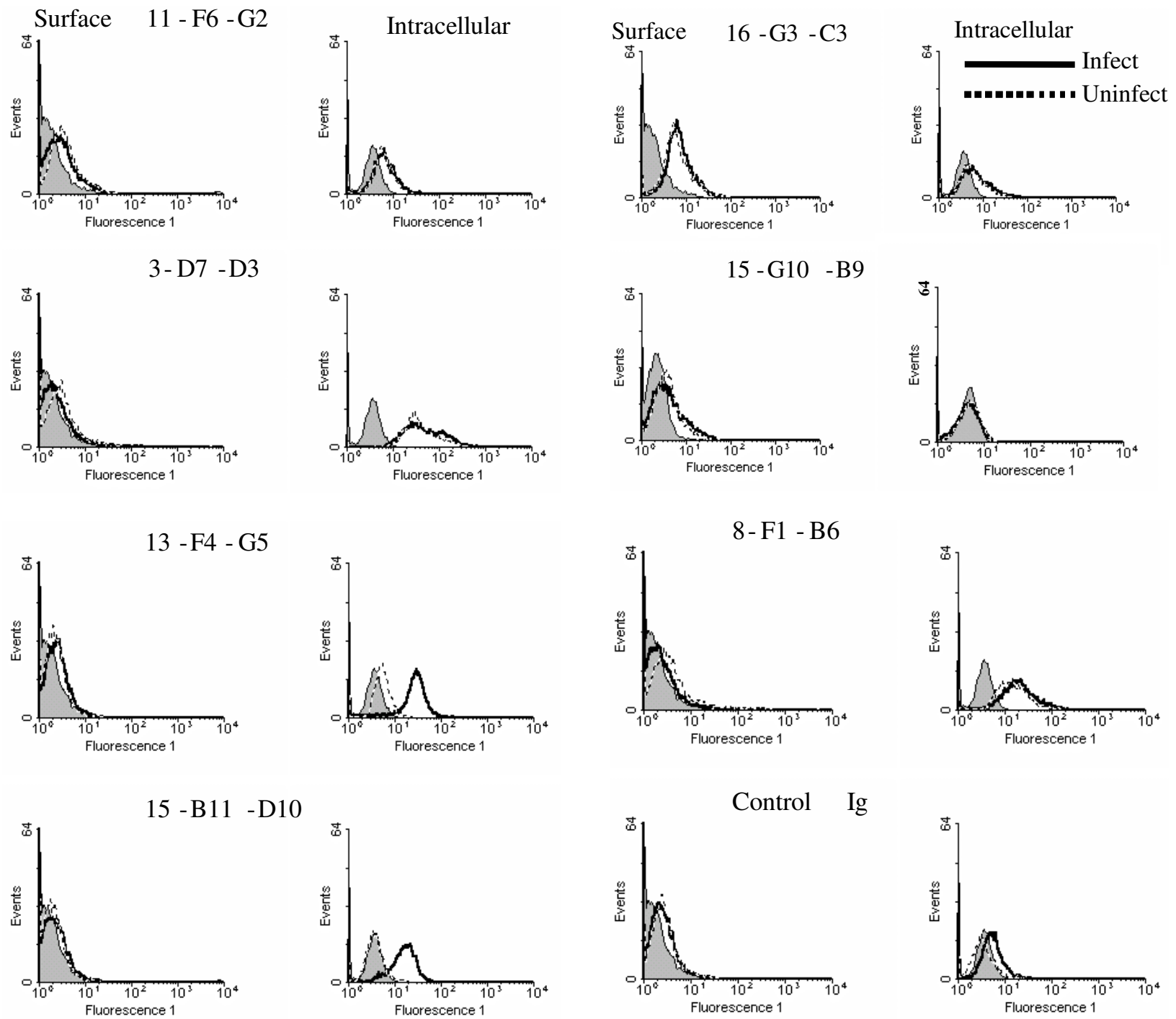

Fig. 5: Flow cytometric analysis of various mAb binding to dengue virus infected BHK cells. BHK cells were infected by dengue virus at m.o.i.of 1 for 24 and then harvested for surface or intracellular staining with various kinds of mAbs as described in materials and methods

Many mAbs that bind NS-1 of dengue virus are cross-reactive with platelets. The binding of platelets can be classified into strong, intermediate and dull three patterns. Either $\operatorname{IgM}$ or $\operatorname{IgG}_{1}$ isotypes are present. Its binding to platelets would induce platelet lysis in the presence of complement, or enhance the ADP-induced platelet aggregation. Furthermore, cross-reactivity between NS-1 and platelet or cellular self-antigen was demonstrated.

Thrombocytopenia is common in dengue fever and is always found in DHF/DSS. The pathogenesis of thrombocytopenia is poorly understood. Either thrombopoiesis in bone marrow was suppressed, or the platelet was destructed. La Russa and Innis suggested that dengue-virus-induced bone marrow suppression depressed platelet synthesis and resulted in thrombocytopenia ${ }^{[4]}$. Wang et al., found that dengue- 2 virus can bind to human platelets in the presence of virus-specific antibody and proposed that the immunemediated clearance of platelets was involved in the pathogenesis of thrombocytopenia in DHF/DSS ${ }^{[5]}$. Virus such as Parvovirus infection is known to be associated with childhood idiopathic thrombocytopenic purpura $^{[14]}$. 


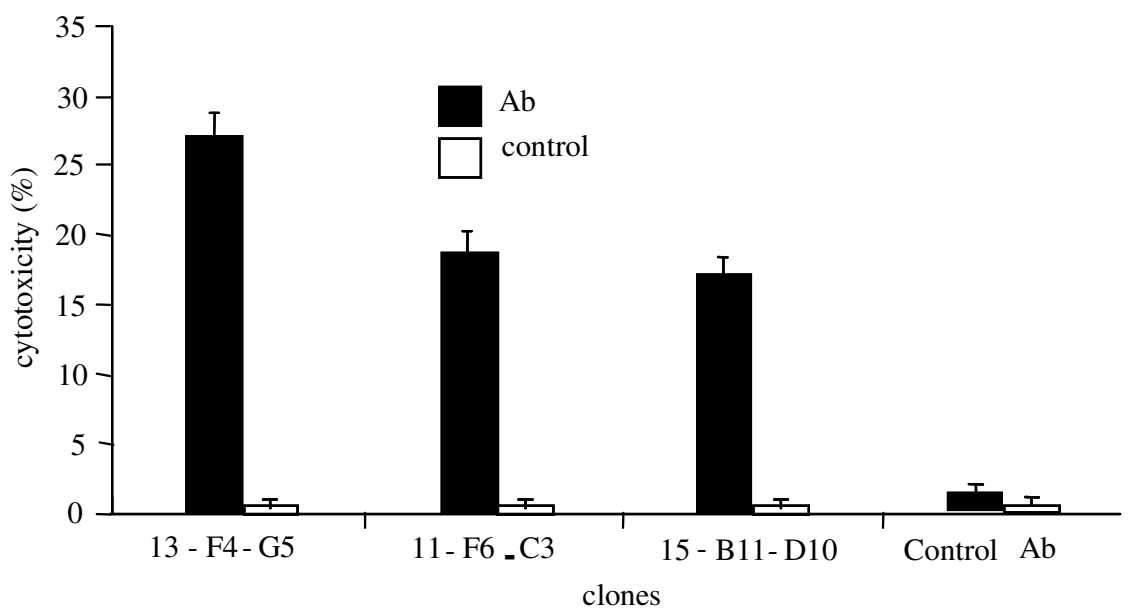

Fig. 6: Anti-platelet monoclonal antibody-mediated complement-dependent platelet lysis. Platelets $\left(\sim 1 \times 10^{8}\right)$ were incubated with purified monoclonal antibodies $(10 \mu \mathrm{g})$ in the presence of rabbit complememt $(1: 25)$ for $4 \mathrm{~h}$ in round-bottom 96 -well plate. The plate was then centrifuged at $1500 \times \mathrm{g}$ for 15 min to collect supernatant. Supernatant $(100 \mu \mathrm{L})$ was assayed for the Lactase Dehydrogenase (LDH) activity with lactase dehydrogenase substrate. Cytotoxicity was calculated following the instruction of the manufacturer's user guide

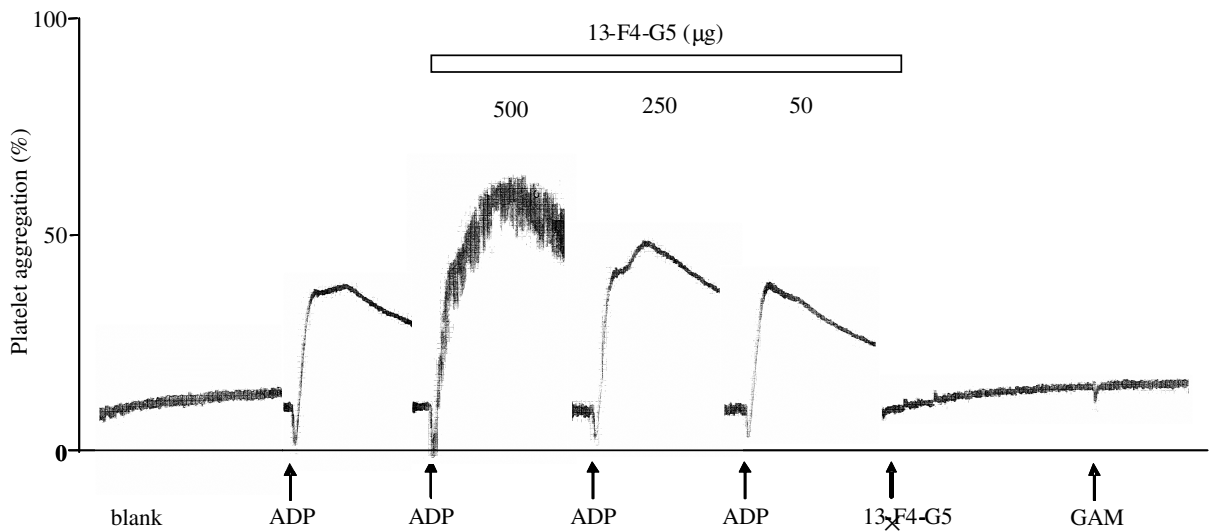

Fig. 7: 13-F4-G5 mAb enhances ADP-induced platelet aggregation. Platelet rich plasma (190 $\mu \mathrm{L})$ was incubated at $37^{\circ} \mathrm{C}$ for $1 \mathrm{~min}$ before addition of $10 \mu \mathrm{L}$ ADP $(100 \mu \mathrm{M})$ agonist or together with indicative amount of monoclonal $\mathrm{Ab}$. In the control, $100 \mu \mathrm{g}$ 13-F4-G5 were injected alone into PRP and crosslinked by addition of goat anti-mouse Ig antibodies (GAM)

Falconar reported monoclonal anti-NS-1 of dengue virus could cross-react with human fibrinogen, thrombocytes and endothelial cells ${ }^{[15]}$. We also found that IgM anti-platelet auto-antibody manifests in dengue patients and its titer is higher in DHF/DSS than in DF patients. The presence of these autoantibodies would induce platelet lysis in the presence of complement $^{[6]}$. The cross-reactivity between dengue virus proteins, especially NS-1 and platelet was further demonstrated using monoclonal antibodies derived from dengue virus-infected mice in this study. Most of the anti-platelet mAbs are reactive to recombinant NS1 , but two of seven clones are NS-1 binding negative. The cross-reactivity between platelet and dengue virus antigens other than NS-1 is not excluded. Although human anti-platelet antibodies are IgM, the panel of mAbs contains $\operatorname{IgG}_{1}$ as well as IgM. The hybridoma fusions are derived from mice that have been infected 
intravenously with dengue-2 virus three or four times. The immunoglobulin class is switch from $\operatorname{IgM}$ to $\operatorname{IgG}_{1}$, but indeed $\operatorname{IgM}$ after multiple infections with dengue virus can be obtained. The generation of anti-platelet antibody during dengue virus infection will cause platelet destruction and results in thrombocytopenia. The antibody-mediated deletion of platelet may play an important role on the manifestation of thrombocytopenia. Furthermore, the molecular mimicry between dengue virus antigen and self-proteins is intriguing and needs further investigation. However, it raises a concern on the immune enhancement or memory of secondary infection. The high affinity of anti-platelet antibody generated after secondary immunization will increase the severity of thrombocytopenia caused by these pathogenic antiplatelet auto-antibodies.

The infection of dengue virus has a risk to develop into DHF or DSS, especially when the serotype of the second infection is different from that of the previous infection. The mechanisms involved in the pathogenesis of DHF/DSS remain poorly understood, although the antibody-dependent enhancement (ADE) hypothesis is proposed to explain this unique clinical phenomenon. $\mathrm{ADE}$ is known as an in vitro observation when a subneutralization amount of antibody is present in the culture with virus ${ }^{[16,17]}$. The virus will enter into the cells through the Fc receptor and the replication of virus in cells will be enhanced. When virion increases, immune deviation such as the production of antiplatelet auto-antibody is triggered. High virus load causes more immune activation. Secondary infection by different serotypes of dengue virus might have more virus load and stronger immune deviation compared to the primary one. The titer of anti-platelet antibodies is higher in DHF/DSS than DF probably because of the immune memory on antibody production. The immune memory or immune enhancement in secondary infection can boost more production of high affinity autoantibody.

Viruses have long been associated with inciting autoimmune disorders. Molecular mimicry is proposed to be one of the pathogenetic mechanisms for autoimmune disease. A similar structure is shared between viral determinants and host antigens. The immune responses against the viral determinant are triggered post infection, which evoke a tissue-specific immune response that is presumably capable of eliciting cell and tissue destruction ${ }^{[18-20]}$. Several virus proteins were mapped to self-antigens such as P2-C protein of coxsackie $B$ virus and glutamate decarboxylase in insulin-dependent diabetes ${ }^{[21-23]}$, viral proteins and $\mathrm{S}$-antigen in experimental autoimmune uveitis $^{[24]}$, coat protein of herpes simplex virus-type 1 and corneal antigens in autoimmune herpes stromal keratitis $^{[25]}$, transaldolase epitope and Epstein-Barr and herpes simplex virus type 1 capsid in multiple sclerosis ${ }^{[26]}$, human cytomegalovirus late protein UL94 and endothelial cell in systemic sclerosis ${ }^{[27]}$.

In parvovirus infection, anti-parvovirus antibodies were reported to react with autoantigens including human keratin, collagen type II, thyroglobulin, singlestrand DNA, cardiolipin and ribonucleoprotein antigen $\mathrm{Sm}^{[28]}$. Among the flavivirus, hepatitis $\mathrm{C}$ virus (HCV) can induce a number of diseases of presumed autoimmune background, like mixed cryoglobulinaemia, glomerulonephritis, panarthritis, arthritis, thyroiditis and skin lesions. In HCV-induced autoimmune hepatitis, anti-liver and kidney microsome autoantibodies directed against cytochrome P450 2D6 and cytotoxic $\mathrm{T}$ cells to $\mathrm{HCV}$ core 178-187 were found $^{[29]}$. The molecular mimicry between NS-1 of dengue virus and self-proteins of platelet is the first example in acute infection of dengue virus. It not only contributes to the pathogenesis of thrombocytopenia, but also raises a critical issue on long-term safety of dengue vaccine. The induction of autoimmunity by dengue virus should be taken into consideration in the dengue virus disease.

\section{ACKNOWLEDGMENTS}

This study was supported by grant NSC89-2318B006-011-M51 from the National Science Council, Taiwan.

\section{REFERENCES}

1. Bhamarapravati, N., P. Tuchinda and V. Boonyapaknavik, 1967. Pathology of Thailand Haemorrhagic Fever: A Study of 100 Autopsy Cases. Ann. Trop. Med. Parasitol., 61: 500-510.

2. Burke, D.S., A. Nisalak, D.E. Johnson and R.M. Scott, 1988. A Prospective Study of Dengue Infection in Bangkok. Am. J. Trop. Med. Hyg., 38: $172-180$.

3. Henchal, E.A. and J.R. Putnak, 1990. The Dengue Viruses. Clin. Microbiol. Rev., 3: 376-396.

4. La Russa, V.F. and B.L. Innis, 1995. Mechanisms of Dengue Virus-induced Bone Marrow Suppression. Baillieres. Clin. Haem., 8: 249-270.

5. Wang, S., R. He, J. Patarapotikul, B.L. Innis and R. Anderson, 1995. Antibody-enhanced Binding of Dengue-2 Virus to Human Platelets. Virology, 213: 254-257. 
6. Lin, C.F., H.Y. Lei, C.C. Liu, H.S. Liu, T.M. Yeh, S.T. Wang, T.I. Yang, F.C. Sheu, C.F. Kuo and Y.S. Lin, 2001. Generation of IgM Anti-platelet Autoantibody in Dengue Patients. J. Med. Virol., 63: 143-149.

7. Huang, K.J., S.Y.L. Li, S.C. Chen, H.S. Liu, Y.S. Lin, T.M. Yeh, C.C. Liu and H.Y. Lei, 2000. Manifestation of Thrombocytopenia in Dengue-2virus-infected Mice. J. Gen. Virol., 81: 2177-2182.

8. Igarashi, A., 1978. Isolation of Singh's Aedes albopictus Cell Clone Sensitive to Dengue and Chikungunya Viruses. J. Gen. Virol., 40: 531-544.

9. Sukhavachana, P., A. Nisalak and S.B. Halstead, 1966. Tissue Culture Techniques for the Study of Dengue Viruses. Bull. WHO, 35: 65-66.

10. Lei, H.Y., M.E. Dorf and C. Waltenbaugh, 1982. Regulation of Immune Responses by I-J Gene Products. II. Presence of both $\mathrm{I}-\mathrm{J}^{\mathrm{b}}$ and $\mathrm{I}-\mathrm{J}^{\mathrm{k}}$ suppressor factors in (nonsuppressor $\mathrm{X}$ nonsuppressor) F1 mice. J. Exp. Med., 155: 955-967.

11. Schwarz, U.R., J. Geiger, U. Walter and M. Eigenthaler, 1999. Flow Cytometry Analysis of Intracellular VASP Phosphorylation for the Assessment of Activating and Inhibitory Signal Transduction Pathways in Human Platelets. Thombosis Haemostasis, 82: 1145-1152.

12. Lei, H.Y., Y.L. Wang, S.C. Lee and S.H. Chen, 1992. The Effect of Pepsin Digestion in Relation to Pre-S Region on Hepatitis B Surface Antigeninduced Hypersensitivity. J. Immunol., 148: 3560-3566.

13. Huang, J.H., J.J. Wey, Y.C. Sun, C. Chin, L.J. Chien and Y.C. Wu, 1999. Antibody Responses to an Immunodominant Nonstructural 1 Synthetic Peptide in Patients with Dengue Fever and Dengue Hemorrhagic Fever. J. Med. Vriol., 57: $1-8$.

14. Heegaard, E.D., S. Rosthoj, B.L. Petersen, S. Nielsen, F. Karup Pedersen and A. Hornsleth, 1999. Role of Parvovirus B19 Infection in Childhood Idiopathic Thrombocytopenic Purpura. Acta Paediatr., 88: 614-617.

15. Falconar, A.K.I., 1997. The Dengue Virus Nonstructural-1 Protein (NS1) Generates Antibodies to Common Epitopes on Human Blood Clotting, Integrin/Adhesin Proteins and Binds to Human Endothelial Cells: Potential Implications in Haemorrhagic Fever Pathogenesis. Arch. Virol., 142: 897-916.

16. Halstead, S.B., 1970. Observations Related to Pathogenesis of Dengue Hemorrhagic Fever. VI. Hypotheses and discussion. Yale J. Biol. Med., 42: 350-362.

17. Halstead, S.B., 1988. Pathogenesis of Dengue: Challenge to Molecular Biology. Sci., 239: 476-481.
18. Manns, M.P. and P. Obermayer-Straub, 1997. Viral Induction of Autoimmunity: Mechanisms and Examples in Hepatology. J. Viral Hepatitis., 4: 42-47.

19. Oldstone, M.B., 1998. Molecular Mimicry and Immune-mediated Diseases. FASEB J., 12: $1255-1265$.

20. Horwitz, M.S. and N. Sarvetnick, 1999. Viruses, Host Responses and Autoimmunity. Immunol. Reviews., 169: 241-253.

21. Atkinson, M.A., M.A. Bowman, L. Campbell, B.L. Darrow, D.L. Kaufman and N.K. MacLaren, 1994. Cellular Immunity to a Determinant Common to Glutamate Decarboxylase and Coxsackie Virus in Insulin-dependent Diabetes. J. Clin. Invest., 94: 2125-2129.

22. Varela-Calvino, R., G. Sgarbi, S. Arif and M. Peakman, 2000. T-Cell Reactivity to the P2C Nonstructural Protein of a Diabetogenic Strain of Coxsackievirus B4. Virology, 274: 56-64.

23. Vreugdenhil, G.R., M.R. Batstra, H.J. Aanstoot, W.J. Melchers and J.M. Galama, 1999. Analysis of Antibody Responses against Coxsackie Virus B4 Protein 2C and the Diabetes Autoantigen GAD(65). J. Med. Virol., 59: 256-261.

24. Singh, V.K., H.K. Kalra, K. Yamaki, T. Abe, L.A. Donoso and T. Shinohara, 1990. Molecular Mimicry between a Uveitopathogenic Site of Santigen and Viral Peptides: Induction of Experimental Autoimmune Uveitis in Lewis Rats. J. Immunol., 144: 1282-1287.

25. Zhao, Z.S., F. Granucci, L.Yeh, P.A. Schaffer and H. Cantor, 1998. Molecular Mimicry by Herpes Simplex Virus-type 1: Autoimmune Disease after Viral Infection. Sci., 279: 1344-1347.

26. Esposito, M., V. Venkatesh, L. Otvos, Z. Weng, S. Vajda, K. Banki and A. Perl, 1999. Human Transaldolase and Cross-reactive Viral Epitopes Identified by Autoantibodies of Multiple Sclerosis Patients. J. Immunol., 163: 4027-4032.

27. Lunardi, C., C. Bason, R. Navone, E. Millo, G. Damonte, R. Corrocher and A. Puccetti, 2000. Systemic Sclerosis Immunoglobulin G Autoantibodies Bind the Human Cytomegalovirus Late Protein UL94 and Induce Apoptosis in Human Endothelial Cells. Nature Med., 6: 1183-1186.

28. Lunardi, C., M. Tiso, L. Borgato, L. Nanni, R. Millo, G. De Sandre, A.B. Severi and A. Puccetti, 1998. Chronic Parvovirus B19 Infection Induces the Production of Anti-virus Antibodies with Autoantigen Binding Properties. Eur. J. Immunol., 28: 936-948.

29. Kammer, A.R., S.H. van der Burg, B. Grabscheid, I.P. Hunziker, K.M. Kwappenberg, J. Reichen, C.J. Melief and A. Cerny, 1999. Molecular Mimicry of Human Cytochrome P450 by Hepatitis $\mathrm{C}$ Virus at the Level of Cytotoxic $\mathrm{T}$ Cell Recognition. J. Exp. Med., 190: 169-176. 